\title{
A POLÍTICA URBANA MUNICIPAL NA REGULARIZAÇÃO FUNDIÁRIA DE LOTEAMENTOS CONSOLIDADOS ANTERIORMENTE À LEI № 6.766/1979
}

\author{
URBAN POLICY ADJUSTMENT IN MUNICIPAL LOTS OF LAND STATEMENT \\ ABOVE THE LAW N ㅇ․ 6.766/1979 \\ Marcelo Rodrigues Mazzei \\ Jonatas Ribeiro Benevides \\ Zaiden Geraige Neto \\ Universidade de Ribeirão Preto - UNAERP - Ribeirão Preto - São Paulo - Brasil
}

Resumo: O presente artigo tem por objetivo o estudo da disposição normativa sobre a regularização fundiária de assentamos urbanos consolidados em período anterior à Lei $\mathrm{n}^{0}$ 6.766/79, com enfoque especial no papel desempenhado pela política urbana municipal. No decorrer do trabalho, serão descritos os aspectos gerais da regularização fundiária no direito brasileiro, bem como será analisado especificamente o procedimento de registro da regularização fundiária dos assentamentos consolidados anteriormente à Lei no 6.766/1979 no Estado de São Paulo. Por fim, será abordado o papel do Município na regularização fundiária inominada, com ênfase na desnecessidade de aprovação de projeto de regularização, emissão de certificação de consolidação e desnecessidade ou não do licenciamento ambiental e urbanístico.

Palavras-chave: Política Urbana. Regularização. Loteamentos.

Abstract: This article aims to study the legislative provision on the regularization of consolidated urban have settled prior to the Law No. 6.766/79, with special focus on the role played by municipal urban policy period. During the work, the general aspects of regularization will be described in Brazilian law as well as will be specifically analyzed the registration procedure of regularization of the settlements previously consolidated with Law No. $6.766 / 1979$ in São Paulo. Finally, we will address the role of the municipality in the innominate regularization, emphasizing no need for regularization design approval, issuance of certification and no need to consolidate or not the environmental and urbanistic licensing.

Keywords: Urban Policy. Regularization. Settlements. 


\section{INTRODUÇÃO}

A ocupação desordenada do espaço urbano no Brasil tem origens históricas. O adensamento populacional aliado à falta de planejamento urbanístico e ambiental, dentre outros diversos elementos, resultaram em milhares de núcleos habitacionais precários e irregulares. Somam-se a esses fatores a rigidez da legislação quanto à regularização fundiária dos loteamentos irregulares, a falta de fiscalizaçãode empreendimentos e a ausência de infraestrutura pública básica em grande parte das cidades.

Como alerta Lígia Melo, "os assentamentos informais, resultado de um processo de ocupação humana em territórios de desenvolvimento urbano degradado e excludente, têm raízes profundas que remontam à formação da sociedade brasileira". (MELO, 2010, p.175)

Com efeito, o crescimento desorganizado de assentamentos irregulares nas cidades brasileiros é produto de processo histórico de falta de políticas públicas voltadas à prevenção de danos ambientais e ao planejamento urbano sustentável e adequado.

Ao tratar especificamente do desenvolvimento do saneamento básico no Brasil, o que pode ser estendido a outros instrumentos urbanísticos e ambientais importantes, Rosely Magalhães de Oliveira aponta que a carência de planejamento urbano, historicamente, começou a dar sinais de ineficiência jána segunda metade do século XIX:

Com a chegada de um grande contingente de imigrantes, que veio se somar à massa de ex-escravos abandonados, aumentou substancialmente a população residente nas cidades, crescendo os problemas relacionados à ocupação urbana sem a correspondente instalação de infra-estrutura de saneamento. Com a abolição da escravatura, em 1888, grande parte dos cerca de 100 mil escravos que trabalhavam nas lavouras de café veio se somar à já crescente população urbana das cidades que eram os principais centros econômicos do país. (OLIVEIRA, 2005, p.129)

É nesse contexto que emerge a importância do estabelecimento global de procedimentos tendentes à legalização e reestruturação de núcleos irregulares. Como esclarece Edésio Fernandes:

Se a produção da moradia informal na cidade não é uma exceção, mas sim um processo estrutural e estruturante do espaço urbano, é 
dessa forma que a questão do desenvolvimento urbano informal tem que ser tratada. Em outras palavras, não cabe tratar da informalidade urbana tão-somente com políticas setoriais ou com programas isolados. Ainda que se deva reconhecer a importância dessas políticas, deve-se buscar conceber uma política de enfrentamento da questão que formule programas de regularização de assentamentos informais consolidados em um contexto mais amplo de política urbana e política habitacional que visem à geração de opções de novas moradias para os setores mais pobres, tanto pelo Poder Público quanto pelo mercado formal. (FERNANDES, 2004, p. 242)

Diversas são as irregularidades passíveis de verificação, como, entre outras, o desrespeito do princípio da continuidade registral pela transferência de imóveis por contratos particulares não registráveis, a ocupação de áreas públicas ou ambientalmente protegidas, o desrespeito à legislação urbanística municipal que trata de obras particulares e o parcelamento irregular do solo realizado à margem da legislação. A mais comum dentre as irregularidades destacas é o parcelamento irregular do solo, consistente na utilização indevida, principalmente por parte do loteador, do instituto jurídico do condomínio comum, como forma de fraudar as disposições legais da Lei nำ6.766/1979.

Dessa forma, o parcelamento irregular do solo é realizado pelo loteador mediante a "venda de pequenas frações ideais de terrenos a diferentes pessoas que não mantinham entre si vínculos que pudessem justificar a compra do imóvel em conjunto, e com atribuição de uma área certa de terreno a cada fração ideal” (SILVA, 2005, p. 143). Essa prática, de há muito, é coibida pelos órgãos públicos responsáveis, inclusive mediante o bloqueio da matrícula imobiliária primitiva, como bem destaca o seguinte precedente da Corregedoria Geral de Justiça de São Paulo:

Registro de Imóveis - Bloqueio de matrícula - Descrição precária da gleba, que não contém todas as medidas lineares perimetrais Ausência de pontos de amarração que permitam a perfeita identificação do imóvel e sua localização geográfica - Evidências, outrossim, de parcelamento irregular do solo - Sucessivas e inúmeras alienações, a pessoas sem qualquer vinculação entre si, de frações ideais individualizadas - Orientação administrativa emanada do Acórdão proferido na Apelação Cível no 72.365-0/7 e enunciada pela E. Corregedoria Geral da Justiça no Proc. CG 2.588/00 - Inteligência do item 151 das Normas de Serviço da CGJ - Bloqueio mantido, ante o risco de prejuízo a terceiros e a necessidade de impelir os interessados rumo à regularização - Fundamento no artigo 214, § 3o, da Lei no 6.015/73 - Provimento negado. (Corregedoria Geral de Justiça de São Paulo - Processo 7.452/2009 - Comarca de Itapecerica da Serra- Corregedor Ruy Pereira Camilo - DJ. 12/02/2009). 
Nesse cenário sobressai a importância do papel do Município na regularização fundiária urbana, já que lhe cabe, constitucionalmente, promover o adequado ordenamento territorial mediante planejamento e controle do uso, do parcelamento e da ocupação do solo urbano (art. 30, inciso VIII da Constituição Federal). Igualmente, tem a responsabilidade de implantar a política de desenvolvimento urbano, com o objetivo de ordenar o pleno desenvolvimento das funções sociais da cidade e de garantir o bem- estar de seus habitantes (art. 182 da Constituição Federal).

Cumpre destacar, pela pertinência, que a jurisprudência do Superior Tribunal de Justiça ainda oscila quanto à definição da responsabilidade do Município quanto à obrigatoriedade da regularização de loteamento clandestinos, mormente no que tange à instauração da infraestrutura local, ostentado precedentes tanto no sentido de que o art. 40 da Lei oㅜ 6.766/1979 fixa um poder-dever ao Município, obrigando-o a regularização o loteamento irregular às expensas do loteador (Resp 1.113.789), quanto no sentido de que art. 40 da Lei $n^{\circ}$ 6.766/1979 Ihe confere a faculdade de promover a realização de obras de infraestrutura em loteamento, sob seu o critério de oportunidade e conveniência (Resp 859.905).

Dentro desse contexto, a atual legislação (em especial a Lei oㅡ 11.977/2009), impõe ao Município, na qualidade de ente federativo, o protagonismo legislativo e administrativo no que concerne à regularização fundiária de parcelamentos urbanos clandestinos consolidados.A regularização fundiária objetiva a adequação da situação fática existente à legislação, observada eventual irreversibilidade ou inutilidade de exigências ambientais ou urbanística para determinado assentamento, consideradas suas características reais. Ao comentar sobre a exegese da Lei no 11.977/2009, Henrique Ferraz de Mello (2013, p. 85) esclarece:

Por primeiro, cabe acentuar que as regularizações fundiárias instituídas pelo diploma em apreço (Lei o 11.977/2009) se voltam, em linhas gerais, para o aproveitamento das situações de fato (assentamentos) já consolidados no tempo e tornadas irreversíveis. Não fosse assim, teríamos a incongruência de admitir em nosso ordenamento jurídico um verdadeiro alvará genérico para a prática de esbulhos, ilícitos urbanísticos e ambientais. 
Os loteamentos irregulares mais antigos, implantados antes da vigência da atual Lei Federal de Parcelamento do Solo (Lei oㅡ 6.766/1979), representam um grave problema a ser enfrentado no intuito da promoção de um planejamento urbanístico adequado. Isso ocorre porque quanto mais antigo é o loteamento, mais antigos são os problemas decorrentes da ausência de um planejamento urbanístico adequado, inclusive, na maioria das vezes, com consequências ambientais desastrosas, além da vulneração do direito de propriedade dos adquirentes dos lotes, como bem observa Edésio Fernandes (2004, p. 244):

\begin{abstract}
Em termos jurídicos, a informalidade urbana tem acarretado todo tipo de implicações, mas destaque especial deve ser dado à questão da falta de segurança da posse; sobretudo em países como o Brasil, onde o registro é constitutivo da propriedade, a falta de títulos registrados está criando sérias dificuldades até para se arrumar emprego. (...) A insegurança jurídica ocorre desde a falta de um endereço até a falta de acesso ao crédito, passando-se por diversas outras formas de dificuldades, colocando a população em uma situação de vulnerabilidade política, e enquanto tal muito mais facilmente submetidas às práticas do clientelismo político.
\end{abstract}

Com base no direito social de moradia (art. 6ำ, caput, da Constituição Federal), pautado na importância para os adquirentes de lotes em antigos assentamentos informais obterem o registro imobiliário de suas propriedades, 0 art. 71 da Lei no 11.977/2009 possibilitou a regularização fundiária das glebas parceladas para fins urbanos anteriormente a 19 de dezembro de 1979 que não possuírem registro. Esses loteamentos deverão, além do requisito temporal, estarem implantados e integrados à cidade, ou seja, devem estar consolidados faticamente. $\mathrm{O} \S 2^{\circ}$ do art. 71 prevê que 0 interessado deverá apresentar certificação de que a gleba preenche as condições previstas no artigo, bem como deverá instruir seu pedido com desenhos e documentos que contenham informações necessárias para a efetivação do registro do parcelamento. A expedição da certificação aludida é de competência do Município.

Nesse ponto reside a problemática abordada no presente trabalho, voltado ao estudo do papel do Município na regularização fundiária de loteamentos irregulares consolidados, implantados antes da vigência da Lei no 6.766/1979, na chamada regularização fundiária inominada ou sumária. 


\section{ASPECTOS GERAIS DA REGULARIZAÇÃO FUNDIÁRIA}

O art. 46 da Lei oㅜ11.977/2009 conceitua regularização fundiária como um conjunto de medidas jurídicas, urbanísticas, ambientais e sociais que visam à regularização de assentamentos irregulares e à titulação de seus ocupantes, de modo a garantir o direito social à moradia, o pleno desenvolvimento das funções sociais da propriedade urbana e o direito ao meio ambiente ecologicamente equilibrado.

A regularização fundiária implica, portanto, na conjugação de medidas jurídicas tendentes à defesa do direito social de moradia, além da proteção ao meio ambiente e da função social da propriedade urbana, inserida esta última dentro de um planejamento urbano sustentável.

O art. 2º, inciso XIV da Lei oㅜ 10.257/2001 (Estatuto da Cidade), prevê na condição de diretriz da política urbana a regularização fundiária e urbanização de áreas ocupadas por população de baixa renda, mediante 0 estabelecimento de normas especiais de urbanização e uso e ocupação do solo e edificação, considerada a situação socioeconômica da população, bem como as normas ambientais.

Dentro do aspecto procedimental, a Lei no 11.977/2009 estabeleceu dois modelos nominados de regularização fundiária: a regularização fundiária de interesse social e a regularização fundiária de interesse específico. Acrescente-se, ainda, a regularização fundiária inominada ou sumária (art. 71 da Lei oㅜ11.977/2009) e a regularização fundiária em imóveis públicos (Lei nº 11.481/2007).

A conceituação de regularização fundiária de interesse social é obtida pela análise da presença dos requisitos constantes do art. 47, inciso VII da Lei no 11.977/2009. O citado artigo determina que a regularização fundiária de interesse social se caracteriza pela na regularização de assentamentos irregulares ocupados, predominantemente, por população de baixa renda, nos casos em que a área esteja ocupada, de forma mansa e pacífica há pelo menos 05 anos; nos casos de se tratar de imóveis situados em zona especial de interesse social (ZEIS) ou no caso de áreas públicas (União, Estados, 
Distrito Federal e Municípios), declaradas de interesse para implantação de projetos de regularização fundiária de interesse social.

Como ensina Henrique Ferraz de Mello (2013, p. 95), para caracterização da regularização fundiária de interesse social, os requisitos constantes no art. 47, inciso VII da Lei no 11.977/2009 "não são cumulativos, mas alternativos".

A definição de regularização fundiária de interesse específico é pautada pela subsidiariedade, ou seja, toda regularização fundiária que não for de interesse social será de interesse específico (art. 47, inciso VIII da Lei no 11.977/2009).

A regularização fundiária poderá ser promovida pela União, pelos Estados, pelo Distrito Federal e pelos Municípios, bem como pelos beneficiários (individualmente ou coletivamente) e por cooperativas habitacionais, associações de moradores, fundações, organizações sociais, organizações da sociedade civil de interesse público ou outras associações civis que tenham por finalidade atividades nas áreas de desenvolvimento urbano ou regularização fundiária (art. 50 da Lei no 11.977/2009). Essa legitimidade abarca todos os atos necessários para a regularização fundiária, inclusive os atos voltados ao registro imobiliário.

\section{O PROCEDIMENTO DE REGISTRO DA REGULARIZAÇÃO FUNDIÁRIA DOS ASSENTAMENTOS CONSOLIDADOS ANTERIORMENTE À LEI № 6.766/1979 NO ESTADO DE SÃO PAULO}

A regularização fundiária de glebas parceladas anteriormente a 19 de dezembro de 1979 (antes da Lei № 6.766/1979) e integradas à estrutura urbana da cidade, chamada doutrinariamente de "regularização fundiária inominada ou sumária", está prevista no art. 71 da Lei no 11.977/2009 e no art. 288-A, § 4º, inciso II da Lei no 6.015/73. Prevê o art. 71 da Lei no 11.977/2009 que asglebas parceladas para fins urbanos anteriormente a 19 de dezembro de 1979 que não possuírem registro poderão ter sua situação jurídica regularizada, com o registro do parcelamento, desde que o parcelamento esteja implantado e integrado à cidade. 
Regulamentando 0 registro imobiliário desses parcelamentos irregulares realizados antes de 19 de dezembro de 1979, o art. 288-A, § 4은, inciso II da Lei no 6.015/73, estabelece que independe da aprovação de projeto de regularização fundiária o registro do parcelamento de glebas para fins urbanos anterior a 19 de dezembro de 1979 que não possuir registro, desde que o parcelamento esteja implantado e integrado à cidade, nos termos do art. 71 da Lei ${ }^{0} 11.977 / 2009$.

Como visto, tanto o art. 71 da Lei ำ 11.977/2009, quanto o art. 288-A, $\S 4^{\circ}$, inciso II da Lei ํo 6.015/73, buscam a regularização fundiária de assentamentos decorrentes de parcelamentos irregulares efetuados antes de 19 de dezembro de 1979, que estejam consolidados no ambiente urbano.As disposições legais sobre a regularização fundiária inominada ou sumária abordam somente os aspectos temporais e de consolidação do assentamento, independentemente de se tratar de regularização fundiária de interesse social ou de interesse específico. Dessa forma, os dois tipos de regularização fundiária (interesse social ou específico), podem se caracterizar como regularização fundiária inominada ou sumária, importando o mesmo tratamento legal.

No Estado de São Paulo, a regularização fundiária inominada ou sumária é tratada no item no 300 das normas extrajudiciais da Corregedoria Geral de Justiça.

O item no 300 prevê que o pedido de registro da regularização fundiária inominada ou sumária deverá estar instruído com certidão do Município atestando que o loteamento foi implantado antes de 19 de dezembro de $1979 \mathrm{e}$ que está integrado à cidade; com planta da área em regularização assinada por profissional legalmente habilitado, com prova de Anotação de Responsabilidade Técnica (ART) no Conselho Regional de Engenharia e Agronomia (CREA) ou de Registro de Responsabilidade Técnica (RRT) no Conselho de Arquitetura e Urbanismo (CAU), contendo as subdivisões das quadras, as dimensões e numeração dos lotes, logradouros, espaços livres e outras áreas com destinação específica, dispensada a ART ou o RRT quando o responsável técnico for servidor ou empregado público; com certidão de 
matrícula ou transcrição da área em regularização e com memoriais descritivos da gleba, da área parcelada, dos lotes, dos bens públicos e das demais áreas.

Ainda conforme as normas extrajudiciais da Corregedoria Geral de Justiça de São Paulo, aplicam-se às regularizações inominadas ou sumárias os institutos relativos à regularização de condomínio de frações ideais, à demarcação urbanística e à legitimação de posse (item nํ300.3).

\section{O PAPEL DO MUNICÍPIO NA REGULARIZAÇÃO FUNDIÁRIA INOMINADA}

A atual legislação buscou transferir aos Municípios o protagonismo legislativo e administrativo no que tange ao procedimento de regularização fundiária dos assentamentos urbanos.

No que se refere à necessidade de aprovação do projeto de regularização fundiária para fins de registro imobiliário, o que inclui o licenciamento urbanístico e ambientalpara as regularizações fundiária de

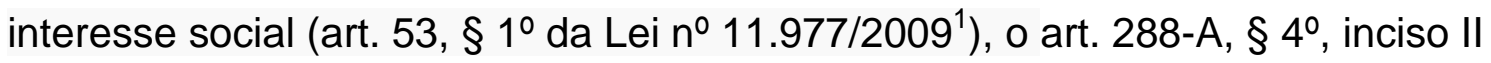
da Lei $n^{\circ}$ 6.015/73 expressamente excluiu a obrigatoriedade de sua aprovação para os parcelamentos irregulares de glebas para fins urbanos concretizados anteriormente a 19 de dezembro de 1979, que estejam implantados e integrados à cidade. Nesse sentido é o entendimento de Henrique Ferraz de Mello (2013, p. 109-116) ao comentar sobre a regularização fundiária inominada:

\footnotetext{
Quer isto dizer que, enquanto as duas primeiras formas de regularização fundiária dependem de projeto e de aprovações urbanísticas e ambientais que a própria Lei 11.977/2009 prescreveu, e nas condições nela previstas, como vimos, aquela que estamos tratando, pertinente ao parcelamento de glebas anterior a 19 de dezembro de 1979 (Lei 6.766/1979), implantado e integrado à cidade, nos termos do art. 71, não dependem de projeto, nem de aprovação de órgão algum. A lei 11.977/2009 dispôs no art. 53 (regularização de interesse social) e art. 61 (regularização de interesse específico) que ambas as duas espécies estão sujeitas à "aprovação do projeto de regularização fundiária" a cargo do Município e da autoridade licenciadora ambiental competente, conforme o caso. Portanto, se para as duas regularizações fundiárias
}

\footnotetext{
${ }^{1}$ O item no 276 das normas extrajudiciais da Corregedoria Geral de Justiça de São Paulo unifica o procedimento de registro do projeto de regularização fundiária de interesse social e específico, possibilitando o licenciamento ambiental e urbanístico por parte do Município.
} 
- de interesse social e de interesse específico - o projeto é condição sinequa non para a instauração de ambos os procedimentos, o mesmo já não ocorre com a regularização fundiária inominada, que, diante de seu procedimento sumário, vem recebendo mesmo por alguns doutrinadores, o título de "sumária". (...) A intenção da lei, sob esse ângulo, não foi senão a de dar moradia aos habitantes da urbe, por meio da validação de todos os loteamentos irregulares e clandestinos anteriores à Lei 6.766/1979, em situações de franca irreversibilidade, dispensando as usuais exigências previstas nas normas urbanísticas e ambientais. (...) Portanto, quando a Lei Federal, no caso, a Lei 11.977/2009, alterada pela Lei 12.424/2011, dispensou o licenciamento ambiental para a regularização fundiária inominada, diante da consolidação da situação de fato anterior a 19.12.1979, o fez, conforme interesse público respaldado na função social da propriedade, entendendo tal situação como irreversível mesmo do ponto de vista ambiental. Essa irreversibilidade decorre de presunção da lei, que, pelo tempo, somado aos demais fatores que ela congrega (ocupação e consolidação no meio urbano) não admite outra solução que não a de transportar para o registro a estrutura fatual consolidada no tempo, pura e simplesmente.(...) Portanto, reafirmamos não haver a lei condicionado a regularização fundiária inominada a qualquer tipo de aprovação urbanística ou ambiental.

É claro que a desnecessidade de aprovação de projeto de regularização fundiária que inclua o licenciamento urbanístico e o ambiental depende da situação fática do loteamento consolidado, tratando-se, portanto, de exceção, conforme já decidiu o Conselho Superior da Magistratura do Tribunal de Justiça de São Paulo no seguinte precedente (Acórdão no 0000034-17.2002.8.26.0224):

\begin{abstract}
Registro de Imóveis - Loteamento clandestino - ocupação irregular do solo com mais de quarenta anos - situação consolidada aplicação da Lei n. 11.977/09 editada no curso do processo administrativo -questões urbanísticas e de meio ambiente adaptadas à especificidade do caso - regularização deferida - Recurso não provido. Declaração de voto do Desembargador GonzagaFranceschini: Dúvida registraria - Recurso ministerial requerendo a reforma do decisum por afronta a legislação urbanística - Loteamento cuja ocupação irregular data de mais de quarenta anos evidenciando a consolidação de situação fática - Direito fundamental de propriedade cujo caráter social deve prevalecer sobre outros de cunho ambiental e urbanístico - inteligência da Lei ํo 11.977/09 Recurso não provido.
\end{abstract}

Note-se, que para efeito de registro imobiliário da regularização fundiária inominada, na forma do art. $71, \S 2^{\circ}$ da Lei $n^{\circ}$ 11.977/2009, faz-se necessária a certificação de que a gleba preenche as condições previstas no caput, bem como desenhos e documentos com as informações necessárias para a efetivação do registro do parcelamento. 
Como bem explica Henrique Ferraz de Mello (2013, p. 124), essa certificação poderá corresponder a um alvará de regularização expedido pela Prefeitura, sendo que o requisito da integração à cidade do loteamento será avaliado em função da compatibilização da estrutura viária implantada, assim como das estruturas de saneamento e outros serviços públicos existentes. Para o autor:

\begin{abstract}
Para a prova de anterioridade à Lei 6.766/1979, exige a norma uma certificação (§ $2^{\circ}$, do art. 71). Cabe à prefeitura emitir essa certificação, pois é ela que deve primar pela fiscalização do uso do solo do Município. (...) O requerimento deverá ser instruído com a prova de que o loteamento se acha implantado e integrado à malha viária urbana, atestando-se, para esse efeito, que se trata de área urbana consolidada nos moldes do art. 47, II, da Lei 11.977/2009, e que possui, no mínimo, dois dos equipamentos de infraestrutura implantados (drenagem, esgotamento sanitário, abastecimento de água potável, distribuição de energia elétrica ou limpeza urbana). Além disso, devem ser juntados desenhos, "rectius", planta(s) e memorial(is) descritivo(s), com todos os demais documentos que forem necessários para se estabelecer o controle de disponibilidade (art. 71, § $2^{\circ}$ ).
\end{abstract}

Para a emissão dessa certificação, como forma de embasar o entendimento do órgão municipal competente no que diz respeito à anterioridade do loteamento à Lei ํo 6.766/1979, poderá ele considerar quaisquer provas admitidas pela legislação, como a existência de lançamentos tributários individualizados (cadastro municipal fiscal), a existência de escrituras de compra e venda, a própria matrícula imobiliária que contenha 0 parcelamento irregular mediante alienação de frações ideais do imóvel, fotos datadas, etc.

O item no 300.2 das normas extrajudiciais da Corregedoria Geral de Justiça de São Paulo aponta que a apresentação da certidão da autoridade municipal atestando que o parcelamento foi implantado anteriormente a 19 de dezembro de 1979 e que está integrado e consolidado à cidade, com irreversibilidade da ocupação, dispensa quaisquer outras manifestações, licenças ou alvarás, inclusive do órgão ambiental estadual. Essa disposição reforça a ideia da dispensabilidade da aprovação do projeto de regularização fundiária e consequente licenciamento no plano urbanístico e no plano ambiental. 
Contudo, em que pese a dispensa do projeto de regularização e consequentemente do licenciamento ambiental e urbanístico, é importante ressaltar que a competência para a expedição da certificação de que trata o art. 71, § 2º da Lei oㅜ 11.977/2009 não impossibilita ao Município a verificação da análise de eventuais melhorias no plano urbanístico ou ambiental do loteamento, mormente quando se tratar de regularização fundiária de interesse específico, onde presumivelmente os beneficiados são dotados de recursos financeiros que possibilitem uma melhoria no local, inclusive com a possibilidade de compensações urbanísticas/ambientais caso exista lei municipal autorizativa para tanto.

Dessa forma, quando passíveis de concretização na realidade fática do loteamento, as melhorias impostas pela Prefeitura devem ser atendidas, tudo em atenção ao interesse público que emana de um meio ambiente sustentável e de um planejamento urbanístico regular. Assim, desde que razoáveis e possíveis, dentro da caracterização peculiar da consolidação urbana do loteamento, medidas tendentes a minimizar eventuais danos ambientais (como a eliminação de fossas sépticas) ou danos urbanísticos (desvirtuamento de áreas) são plenamente exigíveis, especialmente por beneficiar também os ocupantes dos loteamentos irregulares.

A emissão da certificação ficará a cargo dos órgãos municipais competentes, normalmente a Secretaria Municipal do Planejamento e a Secretaria Municipal do Meio Ambiente. Note-se a possibilidade da instituição por lei municipal de uma comissão multidisciplinar específica para a análise e emissão da certificação. Essa comissão poderá ser formada por servidores públicos integrantes das Secretarias Municipais envolvidas no processo de análise da presença dos requisitos legais para emissão da certificação de que trata o art. 71, § 2o da Lei ํo 11.977/2009.

\section{CONCLUSÃO}

Como demonstrado ao longo do presente estudo, é chamada de regularização fundiária inominada ou sumária a regularização fundiária de interesse específico ou até mesmo de interesse social sobre loteamentos 
irregulares implantados antes de 19 de dezembro de 1979 (anteriores à Lei oㅡ 6.766/1979) e integrados à estrutura urbana da cidade. Essa regularização é regulamentada pelo art. 71 da Lei nº 11.977/2009 e pelo art. 288-A, § 4을 inciso II da Lei no 6.015/73.

O registro imobiliário da regularização fundiária inominada independe de aprovação de projeto de regularização fundiária, bem como do licenciamento urbanístico e ambiental, desde que verificada uma situação consolidada e irreversível do loteamento. Por situação consolidada no plano urbanístico, deve-se considerar a integração do loteamento irregular à malha viária urbana, bem como ele deve possuir pelo menos dois equipamentos de infraestrutura implantados (drenagem, esgotamento sanitário, abastecimento de água, distribuição de energia elétrica ou limpeza urbana), na forma dos arts. 47, inciso II e 71 da Lei no 11.977/2009, não existindo, portanto, a remota possibilidade de realocação das famílias residentes no loteamento em outro lugar sem a descaracterização do próprio local. Quando presentes tais circunstâncias, mostra-se inviável a realização do licenciamento urbanístico e ambiental, sendo igualmente dispensável, por força de lei, a apresentação do projeto de regularização fundiária para fins de registro imobiliário.

Contudo, é possível ao Município a imposição de eventuais melhorias no plano urbanístico ou ambiental do loteamento irregular, especialmente quando se tratar de regularização fundiária de interesse específico, onde presumivelmente os beneficiados são dotados de recursos financeiros que possibilitem uma melhoria no local, inclusive com a possibilidade de compensações urbanísticas/ambientais caso exista lei municipal autorizativa para tanto. Tais imposições somente são possíveis quando existente lei autorizativa e quando inexistentes obstáculos fáticos para a sua concretização, sopesada a peculiar situação da consolidação urbana do loteamento em questão. 


\section{REFERÊNCIAS}

ALFONSIN, Betânia; FERNANDES, Edesio. Direito Urbanístico: estudos brasileiros e internacionais. Belho Horizonte: Del Rey, 2006.

AMORIM, Victor Aguiar Jardim de. Direito urbanístico: Legislação urbanística e estatuto da cidade. São Paulo: Barauna, 2011.

BRASIL. Superior Tribunal de Justiça. Recurso Especial. Resp 1.113.789. Segunda Turma. Rel. Min. Castro Meira. Brasília, 16 de junho de 2009. Disponível em:<https://ww2.stj.jus.br/revistaeletronica/ita.asp?registro=2009004 38462\&dt_publicacao=29/06/2009>. Acesso em: 10 jul. 2014.

BRASIL. Superior Tribunal de Justiça. Recurso Especial. Resp 859.905. Segunda Turma. Rel. Min. Cesar Asfor Rocha. Brasília, 1ํㅡ de setembro de 2011. Disponível em:<https://ww2.stj.jus.br/revistaeletronica/ita.asp?registro= 200601248170\&dt_publicacao=16/03/2012 >. Acesso em: 10 jul. 2014.

COSTA, Nelson Nery. Direito municipal brasileiro. 6 ed. Rio de Janeiro: Forense, 2014.

FERNANDES, Edésio. Política Nacional de Regularização Fundiária: contexto, propostas e limites. Revista de Direito Imobiliário, São Paulo, № 56, ano 27, p.241-256, jan-jul. 2004.

GERAIGE NETO, Zaiden. O princípio da inafastabilidade do controle jurisdicional. São Paulo: Revista dos Tribunais, 2003.

MEIRELLES, Hely Lopes. Direito municipal brasileiro. 17 ed. São Paulo: Malheiros, 2013.

MELO, Lígia. Direito à moradia no Brasil. Política urbana e acesso por meio da regularização fundiária. Belo Horizonte: Fórum, 2010.

OLIVEIRA, Rosely Magalhães de. Saneamento e pobreza no Brasil. In: VALLA, Victor Vicente, STOTS, Eduardo Navarro e ALGEBAILE, Eveline Bertino. Para compreender a pobreza no Brasil. Rio de Janeiro: Contraponto, 2005.

PINTO, Victor Carvalho. Direito Urbanístico, $2^{\underline{a}}$ ed. São Paulo: Revista dos Tribunais, 2010.

RECH, Adir Ubaldo e RECH, Adivandro. Direito Urbanístico. Caxias do Sul: Educs, 2010.

SILVA, José Carlos Alves da. Favelas e meio ambiente urbano. In: DALLARI, Adilson Abreu e DI SARNO, Daniela Campos Libório (Coord.). Direito urbanístico e ambiental, 2ª ed. Belo Horizonte: Fórum, 2011. 
SILVA, José Marcelo Tossi. Regularização Fundiária: decisões e normas da E. Corregedoria-Geral da Justiça de São Paulo. Revista de Direito Imobiliário, São Paulo, no 58, ano 28, p.143-159, jan-jul. 2005. 